\title{
ANALYSIS OF BRACE STIFFNESS INFLUENCE ON STABILITY OF THE TRUSS
}

\author{
M. KRAJEWSKI* and P. IWICKI \\ Gdańsk University of Technology \\ Faculty of Civil and Environmental Engineering \\ ul. Gabriela Narutowicza 11/12, 80-233 Gdańsk, POLAND \\ E-mail: markraje@pg.gda.pl; \\ piwicki@pg.gda.pl
}

\begin{abstract}
The paper is devoted to the numerical and experimental research of stability of a truss with side elastic supports at the top chord. The structure is a model of a real roof truss scaled by factor $1 / 4$. The linear buckling analysis and non-linear static analysis were carried out. The buckling length factor for the compressed top chord was calculated and the limit load for the imperfect truss shell model with respect to brace stiffness was obtained. The relation between brace normal force and loading of the truss is presented. The threshold stiffness of braces necessary to obtain the maximum buckling load was found. The truss load bearing capacity obtained from numerical analysis was compared with Eurocode 3 requirements.
\end{abstract}

Key words: buckling load, limit load, brace stiffness, imperfection.

\section{Introduction}

The stiffness of steel trusses is much greater in their plane than out of plane and therefore the structures should be braced against lateral deflection and twisting. Requirements for braces necessary to provide lateral stability of compressed members are presented at code EC3 (2006). The simplified design code requirements allow one to reduce the problem of the truss stability to the analysis of compressed chord or diagonals that are separated from the other truss elements. The effect of the lower chord, verticals and diagonals on the truss stability is neglected. Verticals and diagonals are considered only as vertical supports to the upper truss chord, side bracing of the truss chords is considered as rigid side-support and normal forces in the truss chords are assumed to be constant along their length. As a result of simplifications described above the requirements concerning the number and the stiffness of braces are not precise, because analysis of the whole structure is not taken into account. In the code recommendations the buckling length of the truss chords in the case of the out-of-plane truss buckling can be regarded as the distance between braces.

When the effect of the lower chord, verticals and diagonals, or distribution of the normal force along the truss chords braced by rigid side supports is taken into account the buckling length of the truss top chord can be lower than the distance of braces. Out of plane buckling of trusses was studied by Biegus and Wojczyszyn $(2004)$ or by Iwicki $(2007 ; 2010)$ in the numerical research. Experimental test results for trusses with elastic braces were presented by Jankowska-Sanberg and Kołodziej (2013) or by Krajewski and Iwicki (2013; 2014).

The basic problem in the paper is to find the minimum bracing stiffness to ensure that out-of the truss plane buckling occurs between braces or is prevented and occurs in the truss plane. The full bracing condition may also be defined as the bracing stiffness necessary to obtain the maximal buckling load of the truss, or when an increase in bracing stiffness does not cause any further increase of the buckling load. The

\footnotetext{
* To whom correspondence should be addressed
} 
threshold condition of truss bracing is therefore needed, and such condition in the design codes should be described in an applicable form. A truss with elastic horizontal braces is analyzed. The structure is a model of a real roof truss scaled by factor $1 / 4$. In the numerical analysis buckling load and buckled shape of the truss in relation to the stiffness of braces were investigated. The geometrically and materially non-linear static analysis of various braced trusses was also conducted and limit load (for the imperfect truss model) was found. An innovative element of the paper is a study of the relation between brace normal force and loading of the truss with respect to brace stiffness. The reaction in braces depends on the assumed shape and magnitude of initial imperfections and is important in the design of braces. Selected numerical analyses are verified by experimental tests.

\section{Description of the structure}

In the present research the truss illustrated in Fig.1 was considered. The total length was $L=6.0 \mathrm{~m}$ and the depth $0.44 \mathrm{~m}$ in the middle of the truss and $0.3 \mathrm{~m}$ near the supports. The structure was made of steel with yield strength $350 \mathrm{MPa}$. On one of the marginal supports torsion was blocked. In the numerical analysis the truss was loaded and braced at the top chord in 7 joints or only in the middle of the span. The truss was modeled by beam and shell elements and Autodesk Robot Structural Analysis (2010) or Femap with NX Nastran (2009) program.

a)

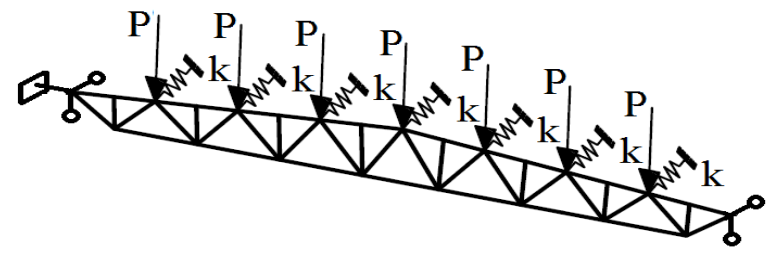

b)

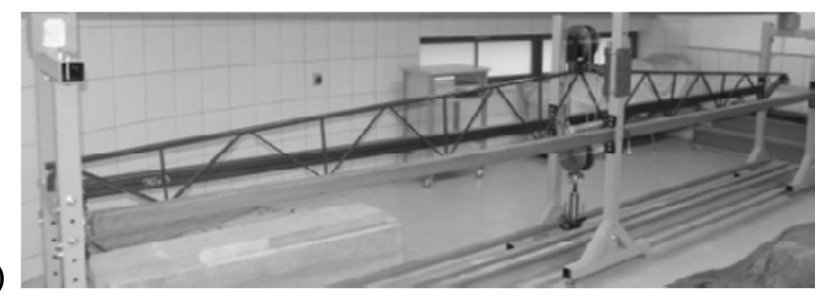

Fig.1. Truss with elastic side supports at the top chord: a) static schema, b) experimental set-up. Cross sections: top and bottom chord $2 \times L 20 \times 3$, U-diagonals and battens $15 \times 10 \times 1.5 \mathrm{~mm}$, square diagonals $15 \times 15 \times 1.5 \mathrm{~mm}$.

The beam model of the truss was made using standard 1D elements with 6 degrees of freedom in a node. Each part of the truss between the joints: diagonals, top chord and bottom chord was divided into 10 elements. In the shell model of the structure 4-node elements QUAD4 were used. The minimum element size was $5.0 \times 5.0 \mathrm{~mm}^{2}$ (Fig.2). RIGID links were used as connections between the truss members. Elastic braces were modeled using DOF-SPRING elements with sliding stiffness only.

In the experimental research the truss was loaded and braced only in the middle of the span (Figs 3a,b). The characteristics for the springs were determined using separate testing (Fig.3c). 
a)

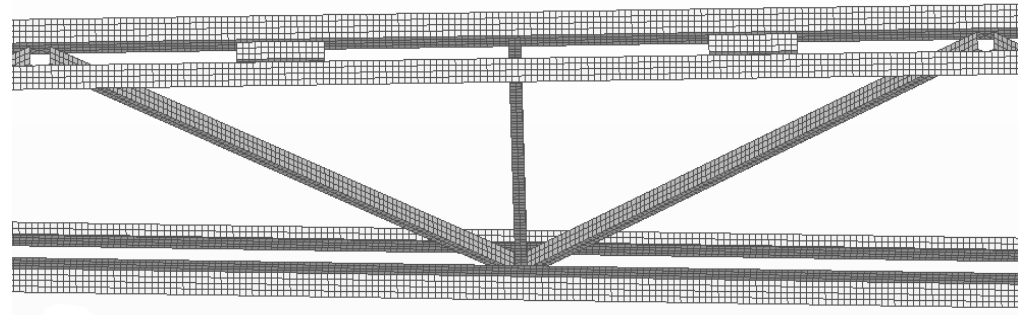

b)

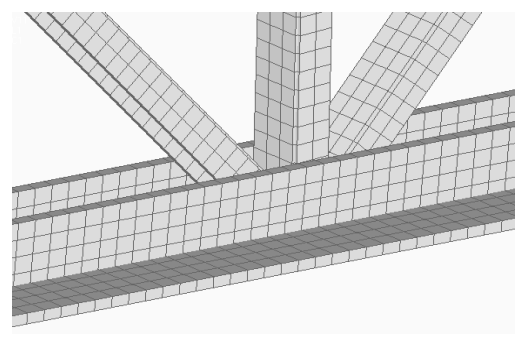

Fig.2. FEM model of the truss: a) front view, b) bottom chord joint detail.

a)

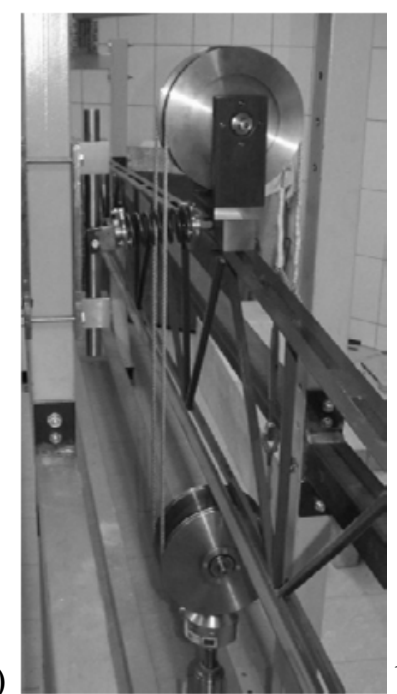

b)

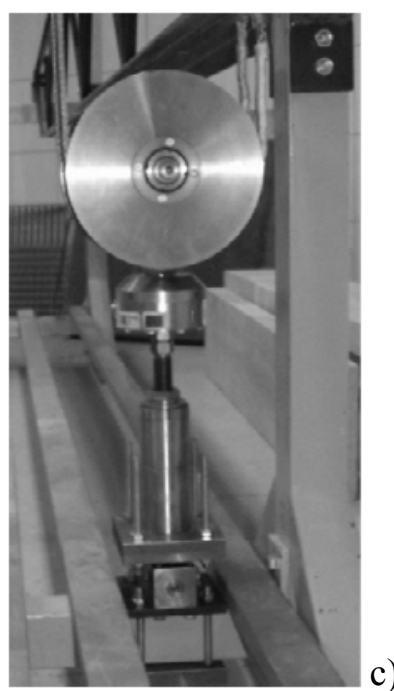

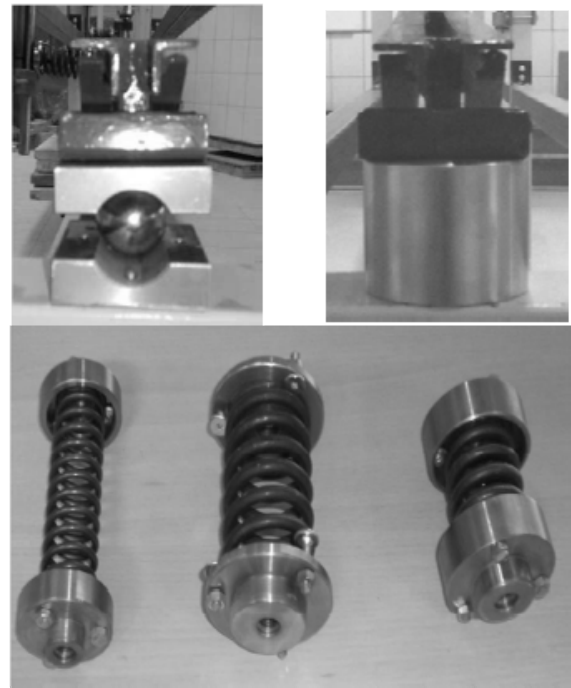

Fig.3. Test set-up detail: a) truss brace, b) force application, c) details at the marginal supports and elastic braces with stiffness (from the left side): $10 \mathrm{kN} / \mathrm{m}, 40 \mathrm{kN} / \mathrm{m}, 80 \mathrm{kN} / \mathrm{m}$.

\section{Numerical analysis results}

\subsection{Linear buckling analysis}

Results obtained from the LBA (Linear Buckling Analysis) are presented in Fig.4. The maximum normal force at the top chord corresponding to the first buckling load was taken into account. The magnitude of the buckling length factor depended on brace stiffness and spacing. The threshold stiffness of braces necessary to obtain the maximum buckling load was: $235 \mathrm{kN} / \mathrm{m}$ for the shell model (with battens), and 130 $\mathrm{kN} / \mathrm{m}$ for the beam model - 7 braces. These differences may be caused by the model of built up cross section of the top chord (influence of battens in the shell model) and also different stiffness of connections between chords and diagonals in 1D and 3D model. The buckled shape of the truss is presented in Fig.5. For the truss with one brace when the threshold brace stiffness was applied $(30 \mathrm{kN} / \mathrm{m})$ the truss buckled out of plane - two half-waves (Fig.5b) and for the structure with 7 braces it buckled locally (most compressed diagonals Fig.5f). 


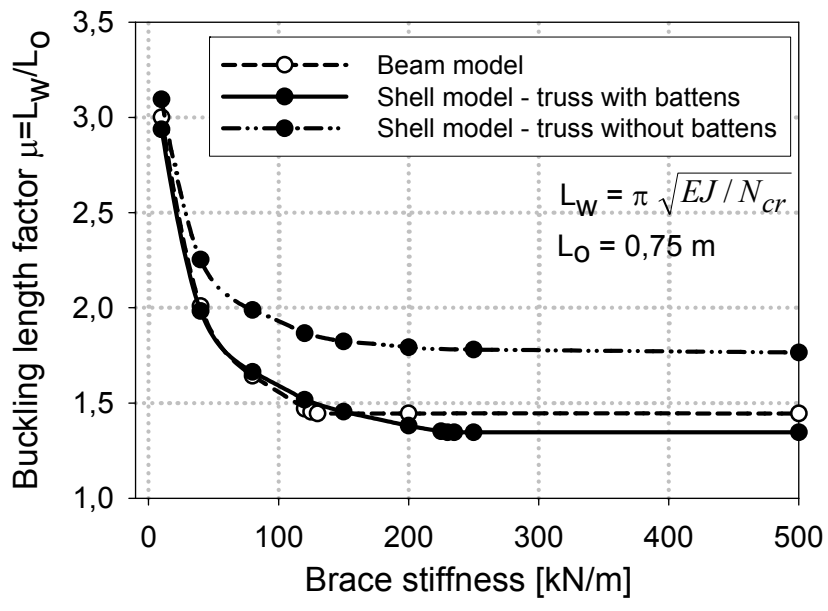

a)

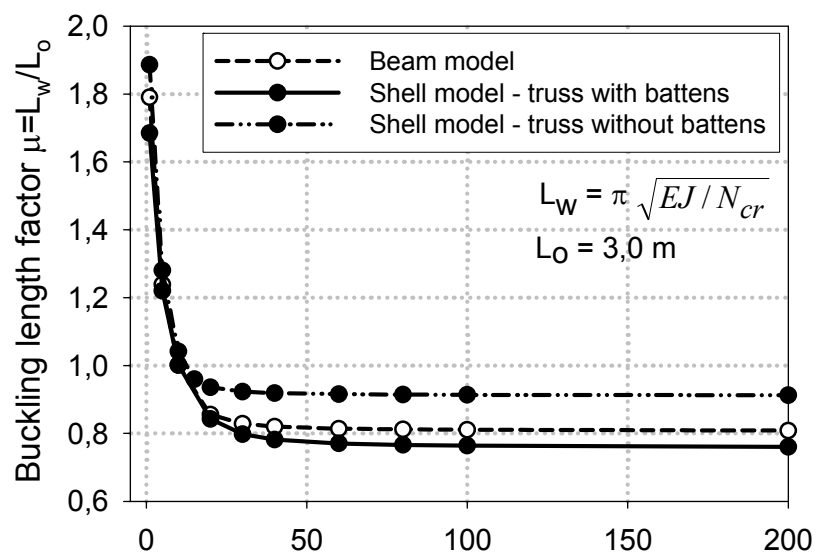

b)

Brace stiffness [kN/m]

Fig.4. Comparison between the buckling length factor for the top chord of the truss with respect to the stiffness of braces for shell and beam model: a) truss with 7 braces, b) truss with 1 brace.

a)

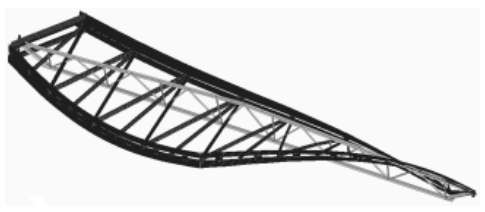

c)
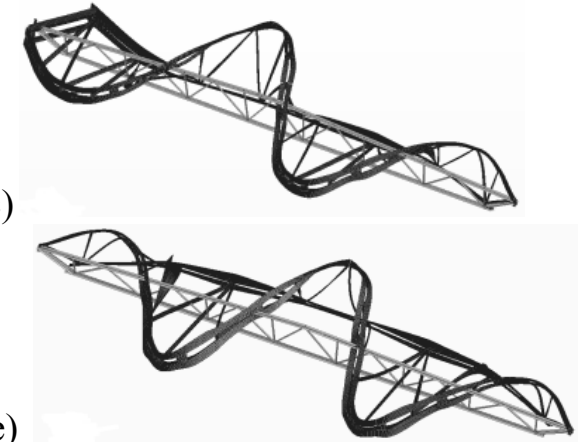

b)

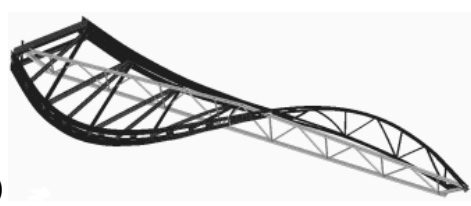

d)

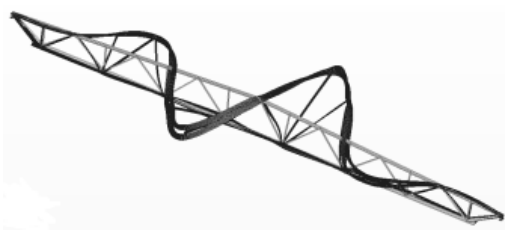

f)

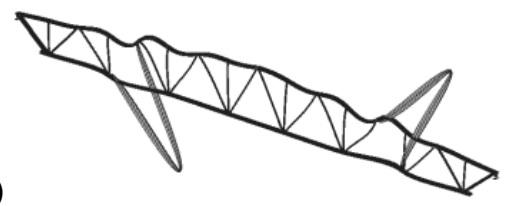

Fig.5. Buckled shape of the truss: a) 1 brace of stiffness $k=10 \mathrm{kN} / \mathrm{m}$, b) 1 brace of stiffness $k=30 \mathrm{kN} / \mathrm{m}$, c) 7 braces of stiffness $k=120 \mathrm{kN} / \mathrm{m}$, d) 7 braces of stiffness $k=120 \mathrm{kN} / \mathrm{m}$ (truss without battens), e) 7 braces of stiffness $k=200 \mathrm{kN} / \mathrm{m}$, f) 7 braces of stiffness $k=235 \mathrm{kN} / \mathrm{m}$. 


\subsection{Nonlinear analysis}

Non-linear static analyses for the imperfect shell model of the truss with 1 brace or 7 braces were carried out. The relation between loading and vertical displacement with respect to brace stiffness determined from GNA (geometrical non-linear analysis) and GMNA (geometrical and material non-linear analysis) is presented in Figs 6, 7. Two types of initial geometric imperfections were considered. The first one - "imperfection I" was assumed as the first buckling mode (LBA) for the truss with different brace stiffness and the magnitude equal to $0.012 \mathrm{~m}$ (L / 500) - EC3 (2006) and PN-EN (2012). The second one "imperfection II" was assumed according to EC3 (2006) as an imperfection of the truss top chord that is bent out of the plane in a shape of a parabolic arch with magnitude of $0.012 \mathrm{~m}$ (Fig.9a).
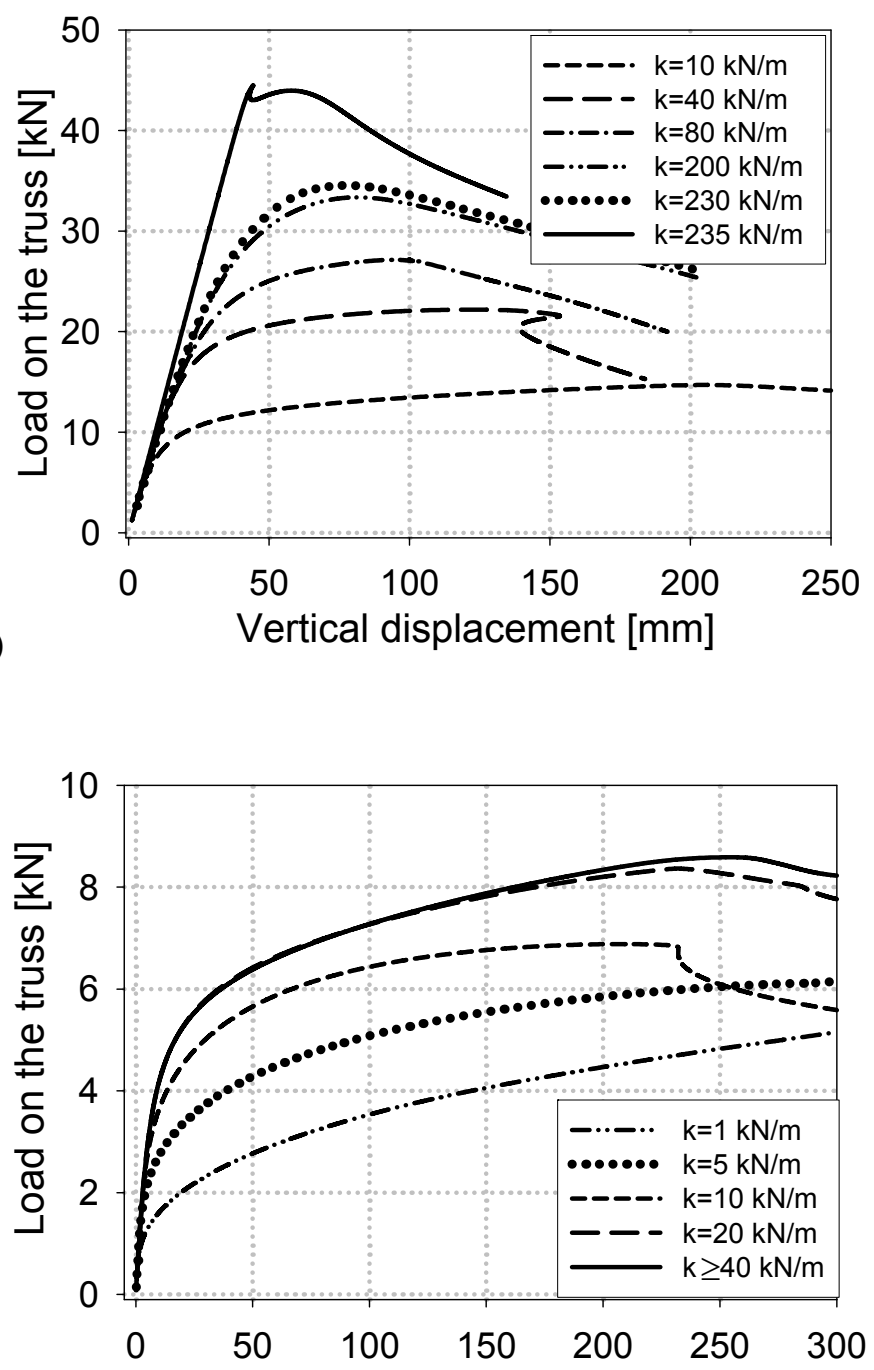

b)

Vertical displacement [mm] 

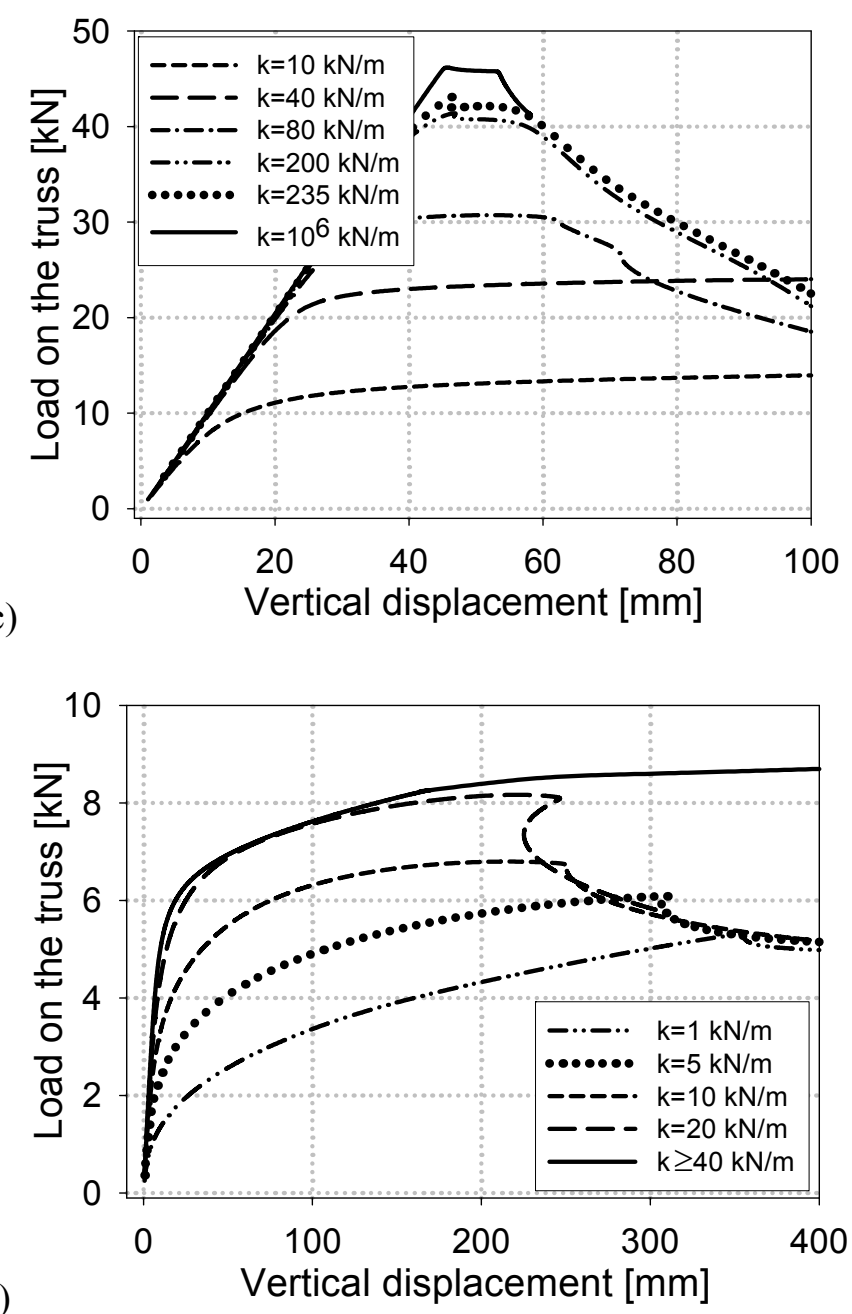

Fig.6. Truss loading due to the vertical displacement (at $1.125 \mathrm{~m}$ from the midspan) for different stiffnesses of side-supports: a) 7 braces GNA - imperfection I (buckling mode), b) 1 brace GNA - imperfection I, c) 7 braces GNA - imperfection II (geometric imperf. due to EC3), d) 1 brace GNA - imperfection II.

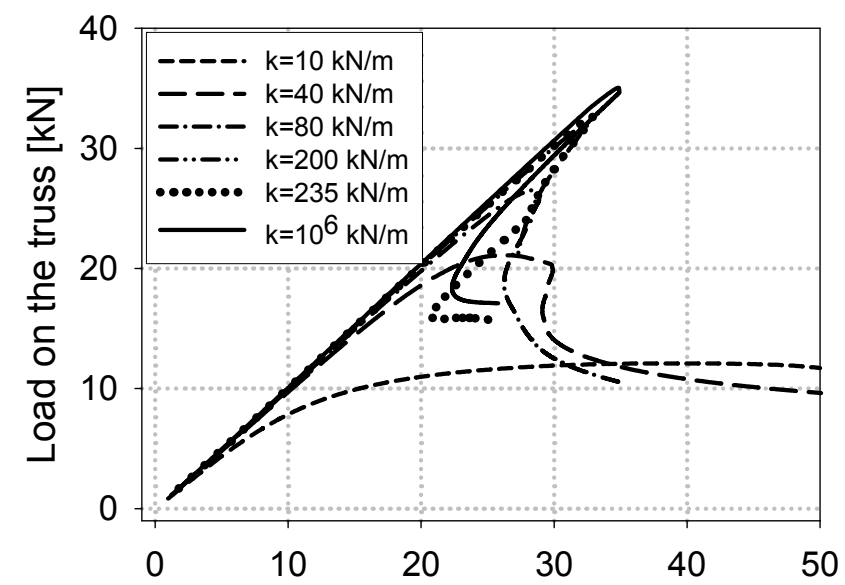

a) Vertical displacement [mm] 


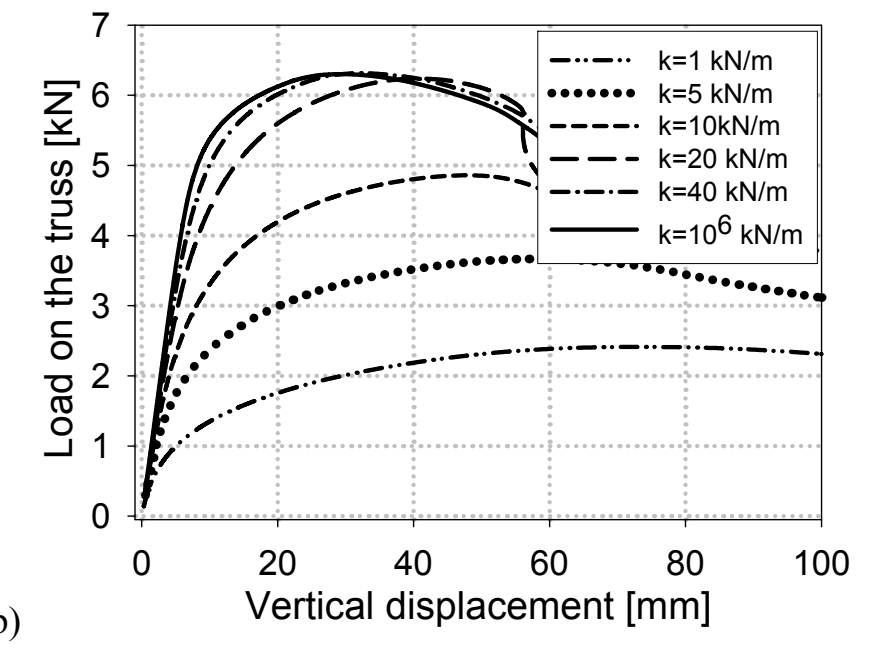

Fig.7. Truss loading due to the vertical displacement (at $1.125 \mathrm{~m}$ from the midspan) for different stiffnesses of side-supports: a) 7 braces GMNA - imperfection II, b) 1 brace GMNA - imperfection II.

For the structure with 7 braces the limit load obtained from GNA and GMNA rises with an increase of brace stiffness (Fig.8). In this case for the threshold bracing stiffness the magnitude of the limit load determined from GNA for truss models with different types of imperfections was similar and it was up to $5 \%$ lower than the buckling load (LBA). The truss load bearing capacity obtained from GMNA was higher than the loading magnitude determined from EC3 (2006) up to $25 \%$ for "imperfection II" and $12 \%$ for "imperfection I" (truss with 7 braces) and $29 \%$ for "imperfection II" and $18 \%$ - "imperfection I" (truss with one brace). This dispersions may be caused by the magnitude and shape of the initial imperfection. In the case of truss with 7 braces (GNA "imperfecion II" for $k=10 \mathrm{kN} / \mathrm{m}$ or $k=40 \mathrm{kN} / \mathrm{m}$ ) and also in the case of truss with 1 brace (GNA "imperfecion I" for $k=1 \mathrm{kN} / \mathrm{m}$ or $k=5 \mathrm{kN} / \mathrm{m}$ and GNA "imperfecion II" for $k=40$ $\mathrm{kN} / \mathrm{m}$ ) the maximum loading magnitude corresponded to vertical displacement magnitude equal to $0.3 \mathrm{~m}$. Truss deformation depending on the brace stiffness and spacing at the limit state is presented in Figs $9 \mathrm{~b}$, c, d, e, f.

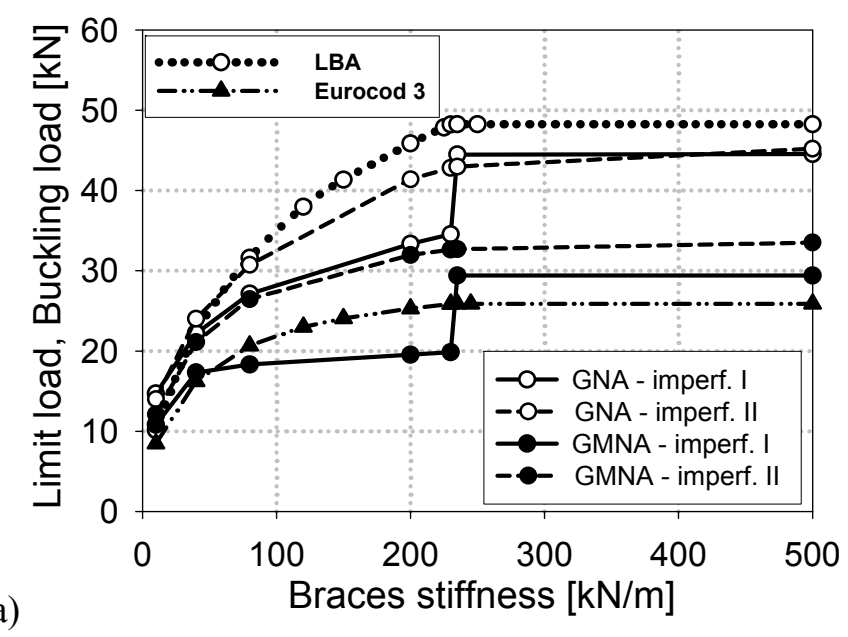




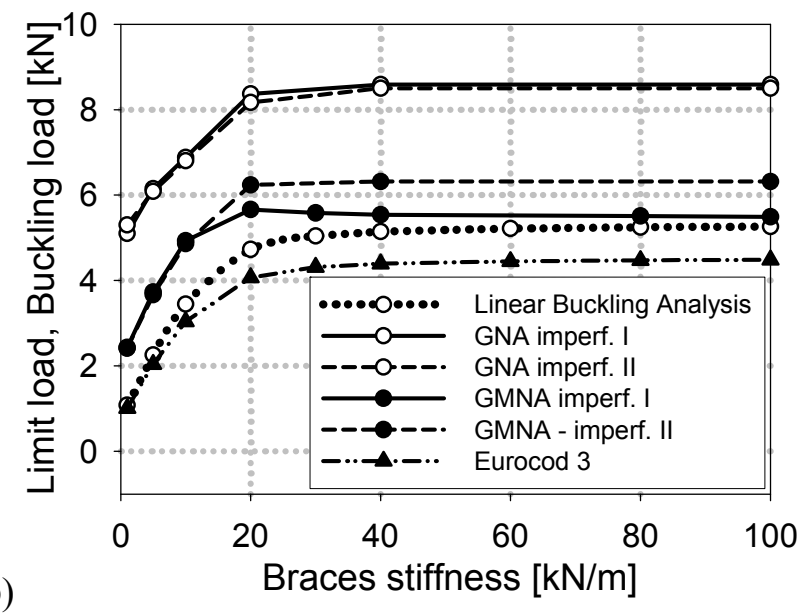

Fig.8. Comparison of the first buckling load and limit load (GNA and GMNA, imperfection I and II) with respect to the brace stiffness for truss with: a) 7 braces, b) 1 brace.

a)

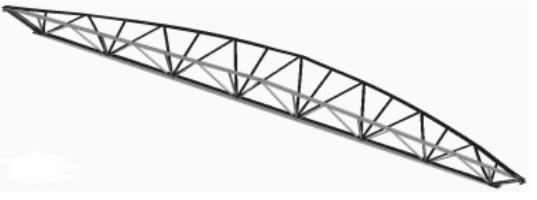

c)

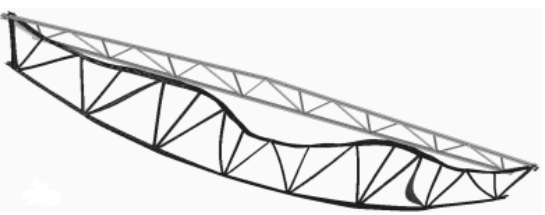

e)

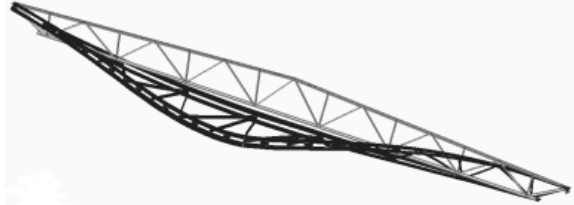

b)

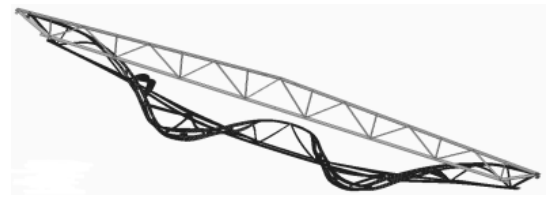

d)

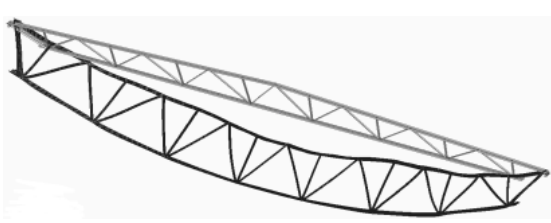

f)

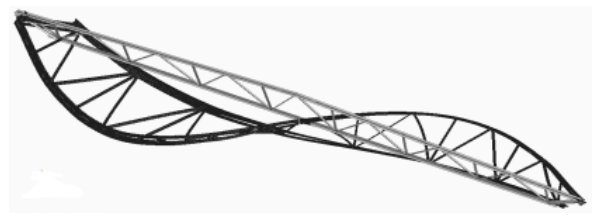

Fig.9. Deformation of the truss: a) initial geometric imperfection according to EC3 (2006) - imperfection II, b) deformation at the limit state for the truss with 7 braces $k=200 \mathrm{kN} / \mathrm{m}$ GNA and imperfection I, c) deformation at the limit state for the truss with 7 braces $k=200 \mathrm{kN} / \mathrm{m}$ GNA and imperfection I (buckling mode), d) deformation at the limit state for the truss with 7 braces $k=200 \mathrm{kN} / \mathrm{m}$ GMNA and imperfection II, e) deformation at the limit state for the truss with 1 brace $k=10 \mathrm{kN} / \mathrm{m}$ GNA,GMNA imperfection I and II, f) deformation at the limit state for the truss with 1 brace $k=40 \mathrm{kN} / \mathrm{m}$ - GMNA, GNA (for vertical displacement $0.3 \mathrm{~m}$ ) imperfection I and II.

The relation between loading and brace normal force (most compressed/tensioned brace in the case of truss with 7 braces) obtained from GMNA imperfection. I and II is presented in Figs 10, 11. The brace normal force decreases or increases after the limit state depending on the deformation of the truss. The maximum brace normal force (at the limit state) obtained from GMNA "imperfection I" was equal to $0.3 \%$ of the top chord normal force. In the case of structure with 7 braces of stiffness $k=235 \mathrm{kN} / \mathrm{m}$ (threshold stiffness) the deformation at the limit state was in the truss plane and therefore the normal force in braces was about $0.0 \mathrm{kN}$. 


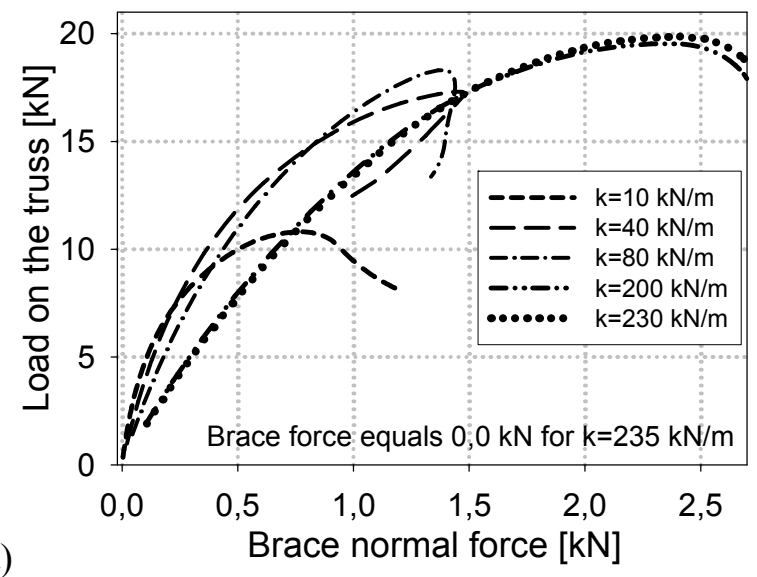

a)

Brace normal force $[\mathrm{kN}]$

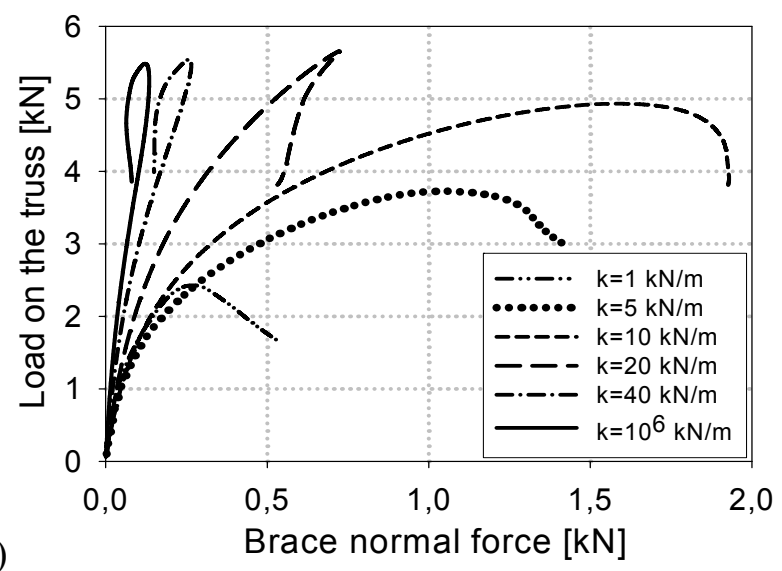

Fig.10. Relation between truss loading and side-supports normal force with respect to brace stiffness for: a) truss with 7 braces GMNA imperfection. I, b) truss with 1 brace GMNA imperfection I.

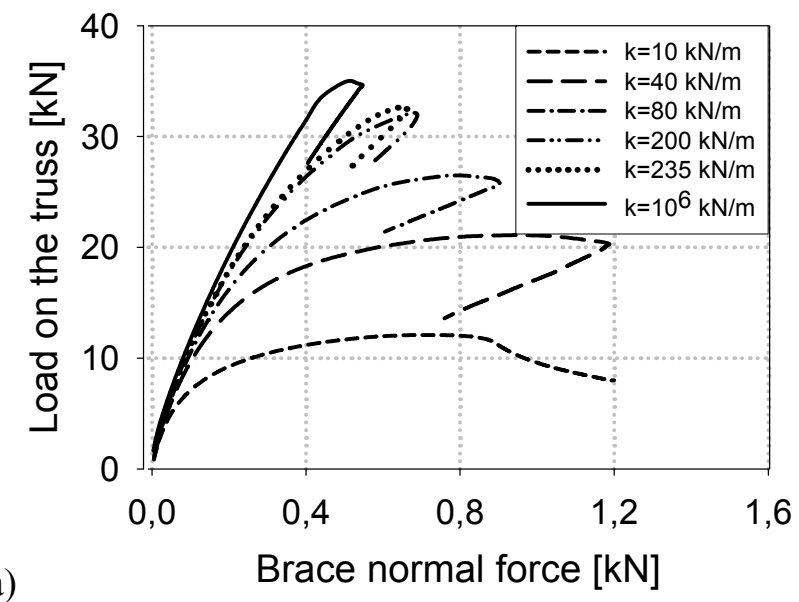




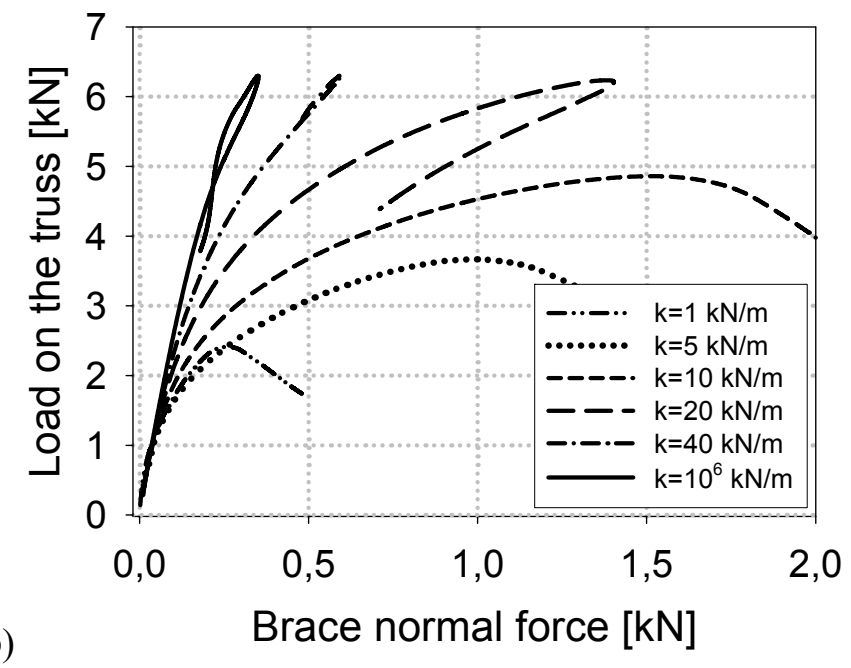

Fig.11. Relation between truss loading and side-supports normal force with respect to brace stiffness for: a) truss with 7 braces GMNA imperfection II, b) truss with 1 brace GMNA imperfection II.

\section{Results of experimental research}

The truss tested experimentally was braced and loaded only in the middle of the span. A brace of stiffness $10 \mathrm{kN} / \mathrm{m}$ was used. The vertical displacement at $1.125 \mathrm{~m}$ from the midspan and horizontal displacement in the middle of top chord were measured. A comparison of numerical analysis and experimental results is presented in Fig.12. The differences may be caused by the servomotor which rotated during the increase of loading but it's horizontal translation was prevented. In this case the out of plane displacements were limited. The reason for the differences may also be the shape and magnitude of geometrical imperfection which was assumed and not measured.

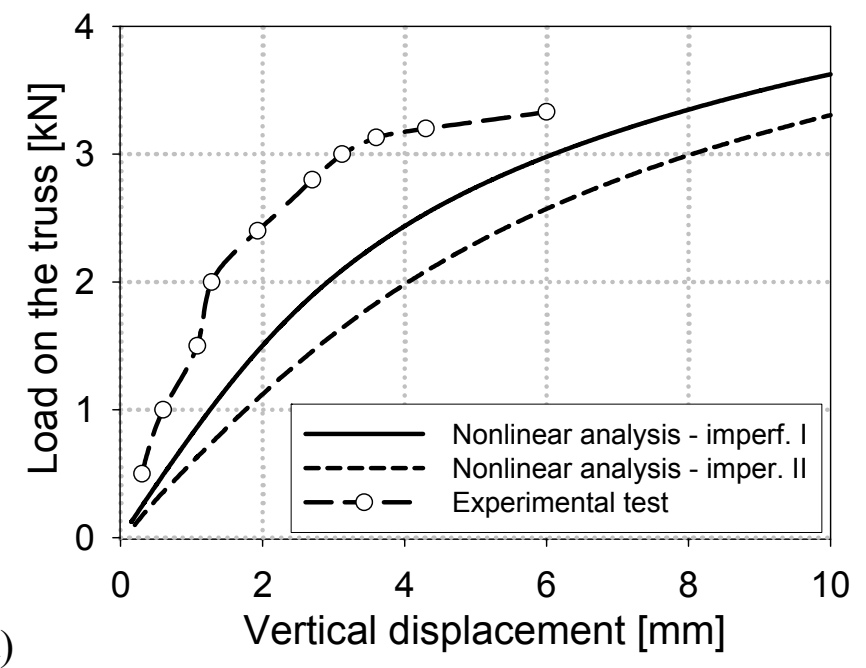

a) 


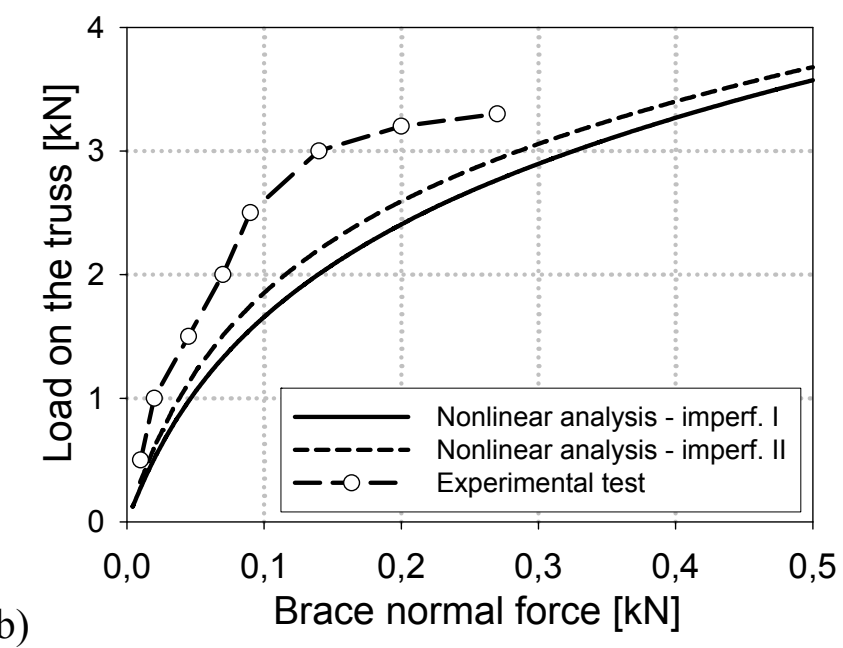

Fig.12. Relation between the truss loading (1 brace, $k=10 \mathrm{kN} / \mathrm{m}$ ) and: a) vertical displacement of the top chord of the truss (measured at 1.125 from the midspan), b) brace normal force.

\section{Conclusions}

Results obtained from the numerical analysis confirmed that the buckling load and limit load depended on brace stiffness and spacing.

The differences between the limit load obtained from GMNA (imperfection I and II) were up to $40 \%$ (for truss with 7 braces of stiffness $230 \mathrm{kN} / \mathrm{m}$ ). The shape of the initial geometric imperfection was in this case very important.

For the truss braced with distance $0.75 \mathrm{~m}$ (7 braces) the magnitude of the buckling load was up to $39 \%$ higher than the limit load obtained from GMNA (imperfection I) for the threshold stiffness of braces. When the distance between braced joints at the top chord was equal to $3.0 \mathrm{~m}$ (truss with 1 brace - only in the middle of the span) the limit load was higher than the buckling load up to $18 \%(\mathrm{k}=40 \mathrm{kN} / \mathrm{m}$, GMNA imperfection II). The dispersions of the above described result may be caused by different range of plastification which was depended on stiffness and spacing of braces (number of supports).

The truss load bearing capacity determined from EC3 (2006) for the threshold stiffness of braces ( $k=30 \mathrm{kN} / \mathrm{m}-1$ brace and $k=235 \mathrm{kN} / \mathrm{m}-7$ braces) was up to $29 \%$ lower than the results obtained from GMNA.

The brace normal force depended on the truss deformation and increased non-linearly (to the limit state). The maximum brace normal force was equal to $0.3 \%$ of the top chord normal force for the truss with 7 braces $(k=230 \mathrm{kN} / \mathrm{m}$, imperfection I) and $0.2 \%$ for the truss with 1 brace $(k=10 \mathrm{kN} / \mathrm{m}$, imperfection I). The brace normal force was equal to $0.0 \mathrm{kN}$ for the truss with 7 braces (imperfection I) and $k=235 \mathrm{kN} / \mathrm{m}$ (threshold stiffness). In this case the most compressed diagonal buckled in the truss plane.

The results obtained from the experimental test and numerical analysis are not coincidental. The modification of the truss loading set-up and measurement of the geometric imperfections from the model made in reality are planed for the future.

\section{References}

Autodesk Robot Structural Analysis Professional (2010). - Autodesk Inc.

Biegus A. and Wojczyszyn D. (2004): Out of plane buckling length for trusses chords. (in Polish) - Inżynieria i Budownictwo, No.11, pp.607-610.

Femap with Nastran N.X. (2009): Finite element modeling and post-processing Version 10.1.1. - Siemens Product 
Lifecyde Management Software Inc.

Iwicki P. (2007): Stability of trusses with linear elastic side-supports. - Thin-Walled Structures, vol.45, No.10-11, pp.849-854.

Iwicki P. (2010): Sensitivity analysis of critical forces of trusses with side bracing. - Journal of Constructional Steel Research 66, pp.923-930.

Iwicki P. and Krajewski M. (2013): 3D buckling analysis of a truss with horizontal braces. - Mechanics and Mechanical Engineering, vol.17, No.1, pp.49-58.

Jankowska-Sandberg J. and Kołodziej J. (2013): Experimental study of steel truss lateral-torsional buckling. Engineering Structures 46, pp.165-172.

Krajewski M. and Iwicki P. (2014): Stability and load bearing capacity of a truss with elastic braces. - Recent Advances in Computational Mechanics, Taylor \& Francis, London, pp.17-22.

EN 1993-1-3 Eurocode 3 (2006): Design of steel structures.- Part 1-1: General rules and rules for buildings.

PN-EN 1090-2+A1 2012. Completion of steel structures and aluminum. Part 2: The technical requirements for steel construction. (in Polish) - Warsaw: PKN.

Received: July 7, 2014

Revised: January 20, 2015 